\title{
Marketing Perspectives on Federal Communications Commission Policies
}

\author{
Steven M. Shugan
}

\begin{abstract}
The author briefly critiques Federal Communications Commission policies and legislative actions as reported by Sappington and Stockdale (2003) and then provides some insights from a marketing science perspective. The author questions whether competition created through regulation produces the same benefits as natural competition and argues that when natural competition fails to produce desired results, the underlying reason might be the prohibitive cost of providing service to some consumers. The author also argues for customer satisfaction measures rather than market measures to determine public policy. The article concludes with a variety of topics for further research in marketing.
\end{abstract}

$\mathbf{S}$ appington and Stockdale's (2003) intriguing article provides fascinating details, motivational insights, and a splendid overview of the inner workings of the Federal Communications Commission (FCC). Few practicing managers or FCC administrators publish in academic journals, and so the article provides a seldom-seen review of the FCC from an academic-economic perspective.

The purpose of this article is to critique FCC policies and legislative actions briefly as reported by Sappington and Stockdale (2003) and attempt to provide some insights from a marketing science perspective. The subsequent discussion is meant to raise issues about the FCC and associated legislation that might spawn academic research in the future. Although this article is sometimes critical, that criticism is directed at legislative directives rather than at Sappington and Stockdale, who only report FCC policy and legislative directives.

\section{Greater Competition Is a Dubious Goal}

It is difficult to argue that truly free markets are remotely undesirable. Observation of markets across different world economies reveals that free markets can have myriad and overwhelming advantages over controlled markets. Free markets can lead to greater efficiencies, innovation, consumer choice, consumer surplus, and social welfare.

In the economics field, competition usually is celebrated as a mystic force in free markets that produces these coveted benefits. Most experienced economists would agree that competition is most likely the consumer's best friend and the individual firm's worst enemy. With the exception of certain illicit actions (e.g., sabotaging competitive facilities, threatening suppliers), intense competition forces indolent firms to be more efficient and more responsive to consumers. Competition also provides a strong incentive for profit-seeking firms to probe the marketing literature for better tools and strategies.

Steven M. Shugan is Russell Berrie Foundation Eminent Scholar and Professor of Marketing, Warrington College of Business, University of Florida.
However, it seems contradictory to strive for greater freedom through greater regulation. When the legislature requires incumbent suppliers of local telecommunications services to provide access to competitive firms, the legislature creates regulated competition: The legislature attempts to create greater freedom within the market, particularly to encourage entry, by controlling the market. The goal is to force partnerships between, for example, owners of physical lines and firms seeking to use those lines. The undertaking brings back memories of the regulated competition of the savings and loan industry, in which regulation insured deposits and competition encouraged risky loans. Remember that long- and short-term social welfare are the objectives and greater competition is only a means to that objective.

As Sappington and Stockdale (2003) note, regulation creates immediate distortions in the investment decisions of incumbent firms, which are unlikely to make gargantuan, highly risky investments unless there exists a reasonable opportunity to enjoy enormous returns from those investments. Firms must have both the rewards of success and the punishments of failure. Moreover, there are complex monitoring problems associated with the degree and quality of the access provided. These complexities certainly should produce unending litigation.

Potentially, however, the most important problem associated with this forced partnership strategy is the renunciation of the most important element of competition, that is, the demise of inefficient suppliers. In the event the incumbent is inefficient and compelled to exit the market, the legislature might be in the precarious position of directly or indirectly subsidizing the incumbent to allow continued service of competitors.

It is important that the partnering relationship is profitable for both parties and that either party can exit the relationship. Many normative articles on channels emphasize both the importance of partnership and solid long-term relationships (e.g., Anderson and Weitz 1989). For example, Jeuland and Shugan (1983) provide mechanisms for channel members to share costs to raise customer service and product quality and to lower consumer prices. Subsequent normative research has moved in similar directions (Ertek and 
Griffin 2002; Kim 2000; Klastorin, Moinzadeh, and Son 2002; Taylor 2002; Weng 1995).

Voluntary partnering relationships do exist in other markets. Firms with access to customers rent and sell that access to third parties, including competitors. For example, consider local supermarkets and convenience stores. These stores carry various products that compete with their own proprietary products. A supermarket carries its own baked goods while providing space to competitive branded goods (e.g., Entenmann's, Sara Lee, Krispy Kreme). Although the Walt Disney Company has a monopoly on food sold in its amusement parks, the firm still allows stand-alone McDonald's restaurants on its property. The key is that the partnership is sufficiently profitable for both firms. Moreover, either firm could exit the market without causing the demise of the partner.

Beyond the paradoxes related to increasing competition through regulation, there is also a dubious relationship between ostensively increased competition and legislative objectives. If natural competition fails to produce a desired result because of latent market characteristics, will competition created through regulation suffer the same outcomes?

When competition intensifies, firms often seek greater efficiencies, which necessitates the flow of resources to more productive activities from less productive activities. One common consequence of marketing activities is the movement of resources from less profitable market segments to more profitable segments. Most commercial marketing research probably is directed at the identification and targeting of profitable and unserved market segments.

With the assumption that artificially created competition, through regulation, is successful in motivating firms to devote more resources to profitable segments, the outcome easily could be antipathetic to legislative objectives. For example, as Sappington and Stockdale (2003) note, legislative objectives mandate access for all people in the United States.

In most cases, existing services in competitive markets fail to reach every consumer because it is unprofitable to serve some (if not most) consumers. The movement of resources (caused by increased competition) results in less adoption, for example, as when many consumers are unwilling to pay sufficiently high prices to induce firms to provide continuous broadband access.

Similar to other industries, enhancing competition probably would fail to yield universal access. Not all consumers have local access to railroads, international airports, libraries, or primary interstate highways. Less than $100 \%$ of all consumers have cable television. In a competitive market, high access costs might make it necessary for some consumers to travel to a different location to obtain high-speed broadband access. Other consumers might obtain access through new technologies such as satellite multicast networks.

It is notable that despite fierce competition (often created by regulatory policy), there now appears to be less access (i.e., fewer locations, shorter hours, and fewer choices) for postal services, airline services (in small towns), health care services, credit unions, and rail transportation services. Indeed, some consumers fail to use socially desirable products even when these products (e.g., seat belts) are made available at low or no cost. Moreover, firms will invest less in product category expansion (i.e., promoting the product category) when their market shares decrease; however, universal adoption of any service or product may or may not be socially desirable.

If the legislature wants to achieve objectives that are deemed socially desirable and fails to provide some consumers with direct subsidies, it must ensure that firms earn monopoly rents in some markets that are sufficient to subsidize unprofitable but socially desirable activities in other markets. In other words, only profitable firms enjoying some monopoly power will be able to absorb the costs that regulation creates.

For example, to persuade banks to make unprofitable loans, it might be necessary to give them greater monopoly power over savings accounts. To persuade airlines to serve unprofitable markets in small cities, it might be necessary to give them greater monopoly power over landing rights in large metropolitan areas. Therefore, to bring about socially desirable objectives by transferring the cost of achieving those objectives to the regulated party, the regulated party requires sufficient profits to absorb those costs; however, competition eliminates the ability of the firms to absorb regulatory costs. Perhaps the government would indirectly pay the cost of regulation through decreased tax burdens.

For better or worse, many existing and potentially socially desirable regulations already adopt this strategy. For example, the added cost of legislated childproof packaging is a transfer of surplus from people without children to those with children. The added cost of legislated automobile air bags is a transfer of surplus from people who prefer less expensive automobiles without air bags to those who prefer luxury autos with air bags as standard equipment, regardless of legislation. The added cost of legislated minimum wages is a transfer of surplus from consumers of lowmargin services delivered by minimum wage employees to consumers of high-margin services delivered by employees who earn more than minimum wage.

There is no doubt that asking firms to transfer consumer surplus from some consumer segments to other consumer segments is a messy business, because it requires sanctioning monopoly rents in some segments, carefully monitoring for abuse, and administering some form of efficacious penalty for insufficiently serving unprofitable segments.

Instead of asking firms to serve unprofitable segments, the legislature could provide direct or indirect subsidies. This alternative probably is preferred because it encourages the socially desirable activities in target markets without creating distortions in other markets (e.g., monopoly prices). For example, the legislature (through the FCC) could subsidize the advertising by new entrants (perhaps by rewarding broadcasters) or directly provide information to consumers about new entrants. This valuable information could lower consumer search costs (Chen, Iyer, and Padmanabhan 2002), which often are high (Mehta, Rajiv, and Srinivasan 2003). With lower search costs, more consumers engage in search and, perhaps, find more desirable service providers. Consumers, in a market with costless search, can locate superior services and abandon inferior services quickly and, thereby, quickly increase consumer welfare and opportunities for efficient new providers. Lower search costs also 
decrease the cost of entry for high-quality firms by lowering their customer acquisition costs. Activities that provide buyers with better information about available alternatives, the potentially critical attributes of those alternatives, and, perhaps, the levels of the attributes can lower search costs. These activities are far less draconian and easier to implement than direct mandates, and they achieve lower costs of entry.

The legislature also could insure the customers of new entrants against the risk of a new entrant's failing and leaving customers with worthless contracts. The legislature alternatively could subsidize access and other costs of the new entrant (e.g., tax credits) to make it profitable for incumbents to sell services to the new entrants. Helping to insure contracts within the channel might substitute for critical reputational effects (Banks, Hutchinson, and Meyer 2002). Finally, the legislature could tax incumbents but give tax credits based on socially desirable outcomes (e.g., the number of customers with access). The key is to provide incentives for the partnerships to work rather than try to force and sustain uneasy partnerships with potentially deceitful and adversarial firms through awkward forms of coercion. One implication is the importance of directly measuring consumer outcomes rather than merely observing market measures of firm concentration.

\section{Consumer Satisfaction Is a Better Goal}

The ultimate goal of the Telecommunications Act of 1996 (47 U.S.C. $\S 151$ ) is to provide consumers with increased access to information. An attempt to increase competition might achieve that objective, and it might not. Remember that, as Sappington and Stockdale (2003) note, most FCC tools for achieving this objective are based on forced sharing of resources and not necessarily the cost of those resources. Although Sappington and Stockdale persuasively argue for some incentive-based regulation, the measures for compliance remain operational in nature. In addition, there is no mention of consumer desires, at which all of the regulation is directed. The operational measures (e.g., Operational Support Systems Preorder Interface Response Timeliness, Order Completion Notifier Timeliness) fail to measure directly consumers' perceptions of performance, attitudes toward the need for better choices, or experiential ideas about deficiencies in the current system. Primary consumer data can be superior to seemingly objective accounting data on sales (Shugan 2002a).

As previously noted, the impact of competition depends on the profits and the incentives of the parties involved. Operational measures might be insufficient to create the proper profits and incentives. It might be necessary both to provide consumers with the necessary information to make prudent choices and to collect information about consumer preferences. For example, if it is socially desirable to increase access, yet consumers are failing to purchase access from local suppliers, it is necessary to learn the reasons consumers are behaving in this way. Only then can an effective remedy be formulated.

For example, it might be a matter of price. As Sappington and Stockdale (2003) reveal, price is often at the center of legislation, litigation, and monitoring. However, simple pricing is uncommon for access services (Essegaier, Gupta, and Zhang 2002). Moreover, there are myriad other factors that might affect consumer behavior, choice of access, and retention (Danaher 2002); in addition, price should not cause preoccupation (Shugan 2002b). Consumers might fear the darker side of high-speed access, including possible theft of information from home computers or possible child endangerment with exposure to inappropriate Web sites or worse. Consumers simply might not find the access particularly valuable, or they might not trust the claims of possibly transitory service providers. Many reasons other than monopolists restricting quantity might inhibit the diffusion of high-speed broadband access. Targeted marketing research solicited either by the FCC or by regulated telecommunications firms could reveal the underlying causes. The valuable identification of those causes would enable the design of an effective strategy with appropriate remedies, which might include, for example, providing consumers with specific forms of information and free software or developing communication protocols.

The marketing literature has a long tradition of surveying customers to determine what they want, but surveying customers involves overcoming difficulties such as determining the appropriate sample, designing questionnaires that provide good measures, and getting consumers to provide accurate responses. However, commercial market research projects overcome these difficulties on a daily basis. Conjoint analysis, for example, can reveal consumer preferences (Sándor and Wedel 2002). Data such as preferred brand sets under different objective environments and preferred product attributes can be invaluable (Yang, Allenby, and Fennell 2002). It is apparent that most industries, including political consulting, view consumer survey information from established market research suppliers as both credible and informative.

Market research might also monitor consumer satisfaction continuously in the market over time (see, e.g., Anderson, Fornell, and Rust 1997). By monitoring consumer satisfaction, it is possible to make the difficult compromises between a coordinated natural monopolist with potential economies of scale and controlled markets with a forced partnership of the monopolist with potentially hostile entrants. Monitoring also provides the channel with appropriate incentives (Chu and Desai 1995) given the appropriate mechanism design (Demski and Sappington 1984). For example, Chu and Desai (1995) explain how to reward service providers on the basis of customer satisfaction indexes.

Although competition can be an excellent tool for increasing consumer welfare, the results of controlled competition created through regulation remain unresolved. However, from what is known in marketing, measures of consumer satisfaction might be linked with incumbent obligations. For example, incumbents losing consumer satisfaction might face restricted actions and limits on increases in market share.

There might be an assumption that increased market share accompanied by decreased consumer satisfaction equals undesirable anticompetitive activities. In contrast, decreased market share accompanied by increased consumer satisfaction suggests a more friendly regulative strategy. Thus, information from customer satisfaction data would be critical in determining whether competition was constructive or 
destructive. The specific penalties or rewards created by the legislature or the FCC are important but are probably outside the scope of marketing research. However, the construction of market-driven performance measures might be well within the scope of marketing research.

Monitoring customer satisfaction also would help pinpoint potential problems such as deteriorating quality or consumer defection to new technologies. It would determine which benefits consumers find enticing and which factors are critical in consumer decision making. An understanding of consumer desires and intended future purchases could guide legislative strategy and determine what (if any) interventions are required. It would also make interventions (i.e., regulation or enforcement) more surgical (i.e., precise and localized) in nature. Finally, a historical collection of customer satisfaction measurements would provide direct evidence about the consequence of industry actions as well as valuable feedback on the results of past markei interventions.

\section{Helping Consumer Make Better Decisions}

Periodic surveys of consumers could provide essential information for many of the other FCC decisions raised by Sappington and Stockdale (2003). That information might be useful in refereeing both industry disputes and convoluted issues regarding jurisdiction. In addition, it might help the FCC determine how to supply technical and market information to confused customers that might increase their welfare and achieve legislative objectives.

To improve consumer welfare, reward higher-quality firms, and inhibit bad consumer choices, the FCC could either provide consumers with information essential to proper decision making or reward incumbent firms for doing so. Execution of this task requires market research to learn what consumers already know and what they need to know, and it requires the formulation of effective strategies for reaching uninformed consumers and for efficiently providing the needed information. For example, market research could determine which media are most effective at reaching the target audiences and the proper format for presenting the information. Information for consumers could be as general as the generic benefits associated with various communication services (e.g., reliability, flexibility, sharing, installation issues, guaranteed price) or the important attributes that consumers should consider in the choice task (Ofek and Srinivasan 2002). Information also could be specific and include comparisons of services from competing firms or different services offered by the same firms. The FCC could give existing firms rewards of some kind for initiating their own informative advertising. The legislature could give firms tax credits for informative advertising (carefully defined within the tax code). For example, informative advertising might be linked to consumer awareness of available choices, consumer understanding of critical product attributes, or other objective consumer measures (this issue requires additional research).

Providing consumers with information enables the FCC to produce performance measures for different firms that would enable consumers to make better, more-informed choices. It would decrease the advertising costs of both new entrants and incumbent firms so there would be less of a deadweight loss in trying to establish credibility with consumers. It would facilitate entry of new firms with superior technology, products, and ideas. The existence of moreinformed consumers would also facilitate the exit of inefficient firms with poor customer satisfaction. Moreover, firms with high FCC ratings would have an incentive both to inform consumers of those ratings and to support (financially and otherwise) the FCC efforts. Alternatively, the FCC might give a private rating service (e.g., Consumer Reports) access to information to encourage it to supply such ratings. Further research on this issue is necessary.

\section{Some Theoretical Directions}

Sappington and Stockdale (2003) inspire several and diverse directions for potential research in marketing. First, more marketing-based methods for measuring consumer welfare should be explored. Traditional economic measures of surplus depend on the difference between the price consumers are willing to pay for something and the actual price paid. However, such a measure ignores postpurchase satisfaction. For example, the traditional consumer surplus measure fails to consider that lowering the cost of fuel or decreasing road congestion increases consumer welfare from currently owned automobiles. Moreover, creating demand through deception should not increase welfare by increasing consumer willingness to pay. Research in marketing has traditionally considered complex measures of consumer utility. It is necessary to develop better ways to use those measures to evaluate public policy.

Second, current market research tools already attempt to forecast the demand for revolutionary new products and imaginative new product concepts. There are also forecasting tools for projecting future sales from early sales and orders data (see, e.g., Moe and Fader 2002). However, the thought-provoking problems facing the FCC might require the development of creative new market research tools, new theories for understanding consumer behavior, and better performance measures for regulated competition.

Some of these new market research tools should emphasize performance evaluation of incumbent firms rather than only try to identify consumer wants. This emphasis on evaluation requires new ways of thinking about service delivery. Rather than trying to identify new attributes for improving service quality or developing revolutionary new services, the focus of market research must shift toward the evaluation of firms' performance. Rather than using traditional techniques to link engineering characteristics to marketing instruments, it becomes increasingly important to construct measures that can endure over time. Consistency across time is important because it is necessary to compare the measures across time and across firms reliably. Measures must remain relevant over time (i.e., continue to measure relevant aspects of performance) so that there is no need to change those measures continually (which is common in traditional market research). These consistent measures should enable meaningful comparisons across time to determine, for example, whether customer satisfaction is improving or declining. That assessment is possible only if the same mea- 
sures are used in each period. Here, consistency across time is as important as or more important than considering only relevancy (see, e.g., Anderson, Fornell, and Rust 1997).

Objectivity is still another critical priority, perhaps as critical as both validity and relevancy. Judgment must be kept to a minimum. Measurement procedures must not be manipulated easily. Measurement procedures must be specified sufficiently so that different market research firms can replicate the procedures at different times.

With appropriate, consistent measures of customer satisfaction, FCC approval of various firm actions (e.g., mergers, acquisitions, alliances between competitors) could be contingent on desirable outcomes such as increased customer satisfaction. Although the type and administration of rewards and penalties need considerable exploration, in the extreme, severe deterioration of consumer surplus might result in forced divestitures or termination of probationary approvals.

Beyond the development of customer satisfaction measures, another third critical issue involves information dissemination as a routine regulatory function. Consumers can make better decisions with better information. Often, it is not until performance fails that consumers learn of a service provider's other inadequacies. Billing errors can either be quickly resolved or produce endless consumer frustration; service delivery failures can either be quickly resolved or produce endless consumer frustration. Merely monitoring and making available information on these unobservable customer satisfaction points might have a dramatic impact on the performance of service providers. Such information would reward quality firms by making customer acquisition easier. The best way to implement that dissemination, by evaluating the effectiveness of that dissemination and the resulting impact on consumer welfare, awaits creative research in marketing.

When simple dissemination of information is insufficient, public policymakers might turn to certification as an option. Indeed, certification is a common function of public policymakers who grant licenses and permits for various services. Consumers often find it difficult to observe provider assets, expected durability, reliability, and past maintenance. Government licensing provides consumers with minimum expectations for future performance. Licenses reduce the consumer costs for evaluating potential future performance. In many markets, service providers must secure licenses to enter the market. In other markets, possession of a license is a signal of quality.

A different issue, possibly worthy of further research, involves consumer attribution. Because of the complexity of the telecommunications industry, with its existing interlinking networks of complex competitive and synergistic relationships, it is difficult to identify the culprit of a deficiency in delivered performance. For example, although consumers might view a new entrant as apparently lacking in performance, the root cause might be incumbent intermediaries' failing to adequately open or operate their networks in compliance with their statutory obligations. Frustrated consumers might have great difficulty correctly attributing failure either to a lack of appropriate service by the new entrant or to a lack of compliance by the incumbent. It would be worthwhile to investigate how consumers form attributions in this complex setting, how those attributions affect consumer decisions, and how those attributions might be influenced. Attributions are relevant to understanding the politics of regulation and the impact of firms' actions on consumers' perceptions of the need for regulation and the effectiveness of current regulation.

Another potential research question pertains to the relationship between consumer satisfaction and traditional measures of competition. One question is whether industry concentration is strongly correlated with customer satisfaction. Perhaps two competing firms might be sufficient to produce high levels of customer satisfaction. Perhaps one firm might be sufficient when there are substantial consumer benefits associated with standards and when competition exists between standards. Perhaps the threat of entry to a monopolist (i.e., one of Porter's [1980] five forces) is sufficient for the monopolist to produce the benefits of multiple competitors.

Another worthwhile research topic is the impact of telecommunications bundles on consumer welfare and firm profitability. It is becoming common to add high-margin add-on services to basic services. A third-party firm sometimes offers add-on services to the customer either directly or invisibly through the main supplier. The most prevalent view in economics is that these bundles represent simple price discrimination. However, the marketing literature often views bundles as far richer, because they can represent carefully chosen options that should appeal to a particular market segment. In choosing the bundle, the segment enjoys a lower cost of deciding which options to select (Shugan 1980). Given the consumption of current components, bundles can represent commitments of customers to use future components. Bundles also can produce cost efficiencies that strike a compromise between costly extreme customization and the forced conformity of complete standardization (Anderson and Shugan 1991). Indeed, almost every product and service is a bundle of components, parts, materials, and lesser services that combine to create greater utility than the sum of the individual components (just as articles are more than the sum of individual words). These different perspectives on bundles can imply diametric attitudes about the desirability and interpretation of bundling from a consumer welfare perspective.

The issues about how to implement add-on or maintenance services and the consequent impact on consumers are areas deserving some attention. In many markets, the basic services bring consumers to the service provider, which later enjoys substantial profits from high-margin add-on services-the old "sell the razor at a loss but make the profit on the blades" idea. Beyond selling exhibition, movie theaters earn substantial profits from concessions, video games, and other add-on services. Cosmetologists provide free consulting services on the latest beauty techniques while earning profits from the sale of cosmetics. Cellular phones are sold at a loss with commitments to time plans. (It is notable that equipment, such as telephones, is discounted when purchased with telecommunications service contracts, but other products, such as eyeglasses, are sold at premium prices when purchased with the corresponding discounted service, such as eye exams.) The social and consumer welfare implications of these practices are unclear. This activity could be 
a form of bait and switch (or, more appropriate, bait and "lock in"), or it could be a way of tailoring services to different segments. The impact on consumers is unclear, and the topic awaits further research.

Still another research topic is the marketing and servicing of long-term contracts between consumers and telecommunications firms. Advance selling of services is becoming common as improved technology lowers administrative costs (Xie and Shugan 2001). Little is known about (1) the impact of advance selling on consumer welfare, (2) how firms establish long-term credibility regarding both the future delivery of services and the future costs of that delivery, (3) how and what consumers view as credible, and (4) how consumers compromise between future flexibility and current commitments with guaranteed discounted future services. Recent research suggests that the practice of advance selling and consumer long-term commitments is highly profitable for firms and possibly beneficial to consumers (Xie and Shugan 2001). Perhaps public policymakers can foster beneficial long-term relationships by providing certifications, guaranteeing agreements, auditing claims, and providing public venues for disseminating customer opinions.

Finally, note that the cost of measuring customer satisfaction could be partially borne by the players in the market that might provide questionnaires or fund independent studies to establish their own performance. Under the direction and standards of the FCC, the entire industry could work synergistically to provide telecommunications consumers with better information for making choices among available services and extracting greater utility from their current services. Certainly, the more efficient and high-quality firms will have an adequate incentive to participate in any FCC activities that potentially influence consumers. Moreover, perhaps, appropriate rewards and penalties could be found to encourage participation in socially desirable activities.

\section{References}

Anderson, Erin and Barton A. Weitz (1989), "Determinants of Continuity in Conventional Industrial Channel Dyads," Marketing Science, 8 (4), 310-23.

Anderson, Eugene W., Claes Fornell, and Roland T. Rust (1997), "Customer Satisfaction, Productivity, and Profitability: Differences Between Goods and Services," Marketing Science, 16 (2) $129-45$.

and Steven M. Shugan (1991), "Repositioning for Changing Preferences," Journal of Consumer Research, 18 (2), 219-32.

Banks, Darryl T., J. Wesley Hutchinson, and Robert J. Meyer (2002), "Reputation in Marketing Channels: RepeatedTransactions Bargaining with Two-Sided Uncertainty," Marketing Science, 21 (3), 251-72.

Chen, Yuxin, Ganesh Iyer, and V. Padmanabhan (2002), "Referral Infomediaries," Marketing Science, 21 (4), 412-35.

Chu, Wujin and Preyas S. Desai (1995), "Channel Coordination Mechanisms for Customer Satisfaction," Marketing Science, 14 (4), 343-59.
Danaher, Peter J. (2002), "Optimal Pricing of New Subscription Services: Analysis of a Market Experiment," Marketing Science, 21 (2), 119-38.

Demski, J. and David Sappington (1984), "Optimal Incentive Contracts with Multiple Agents," Journal of Economic Theory, 33 (1), 152-71.

Ertek, Gurdal and Paul M. Griffin (2002), "Supplier- and BuyerDriven Channels in a Two-Stage Supply Chain," IIE Transactions, 34 (8), 691-700.

Essegaier, Skander, Sunil Gupta, and Z. John Zhang (2002), "Pricing Access Services," Marketing Science, 21 (2), 139-59.

Jeuland, Abel P. and Steven M. Shugan (1983), "Managing Channel Profits," Marketing Science, 2 (3), 239-72.

Kim, Bowon (2000), "Coordinating an Innovation in Supply Chain Management," European Journal of Operational Research, 123 (3), 568-84.

Klastorin, T.D., Kamran Moinzadeh, and Joong Son (2002), "Coordinating Orders in Supply Chains Through Price Discounts," IIE Transactions, 34 (8), 679-89.

Mehta, Nitin, Surendra Rajiv, and Kannan Srinivasan (2003), "Price Uncertainty and Consumer Search: A Structural Model of Consideration Set Formation," Marketing Science, 22 (1), $58-84$.

Moe, Wendy W. and Peter S. Fader (2002), "Using Advance Purchase Orders to Forecast New Product Sales," Marketing Science, 21 (3), 347-64.

Ofek, Elie and V. Srinivasan (2002), "How Much Does the Market Value an Improvement in a Product Attribute?" Marketing Science, 21 (4), 398-412.

Porter, Michael E. (1980), Competitive Strategy. New York: The Free Press.

Sándor, Zsolt and Michel Wedel (2002), "Profile Construction in Experimental Choice Designs for Mixed Logit Models," Marketing Science, 21 (4), 455-75.

Sappington, David E.M. and Donald K. Stockdale (2003), "The Federal Communication Commission's Competition Policy and Marketing's Information Technology Revolution," Journal of Public Policy \& Marketing, 22 (Spring), 00-00.

Shugan, Steven M. (1980), "The Cost of Thinking," Journal of Consumer Research, 7 (2), 99-111.

369-78

(2002a), "In Search of Data," Marketing Science, 21 (4),

(2002b), "Marketing Science, Models, Monopoly Models, and Why We Need Them," Marketing Science, 21 (3), 223-29.

Taylor, Terry A. (2002), "Supply Chain Coordination Under Channel Rebates with Sales Effort Effects," Management Science, 48 (8), 992-1107.

Weng, Z. Kevin (1995), "Channel Coordination and Quantity Discounts," Management Science, 41 (9), 1509-22.

Xie, Jinhong and Steven M. Shugan (2001), "Electronic Tickets, Smart Cards, and Online Prepayments: When and How to Advance Sell," Marketing Science, 20 (3), 219-43.

Yang, Sha, Greg M. Allenby, and Geraldine Fennell (2002), "Modeling Variation in Brand Preference: The Roles of Objective Environment and Motivating Conditions," Marketing Science, $21(1), 14-31$. 
Copyright of Journal of Public Policy \& Marketing is the property of American Marketing Association and its content may not be copied or emailed to multiple sites or posted to a listserv without the copyright holder's express written permission. However, users may print, download, or email articles for individual use. 